\title{
Randomness in Ecological evolution: the role of complexity on the
} Allee effect

\author{
Marcelo Pires $^{1}$, Nuno Crokidakis ${ }^{2}$, and Silvio Duarte Queirós ${ }^{1}$ \\ ${ }^{1}$ Centro Brasileiro de Pesquisas Fisicas \\ ${ }^{2}$ Universidade Federal Fluminense
}

August 17, 2020

\begin{abstract}
Considering an ecological Allee-like dynamics under linearly uncorrelated perturbations with random and nonrandom temporal arrangements we show that a complexity measure, rather than the standard autocorrelation function, is able to properly explain the fate of extinction and to what extent the threshold establishing the risk of extinction. Accordingly, these results allows comprehending $\backslash$ emph $\{$ how $\}$ randomness jeopardises the long-run proliferation of organisms.
\end{abstract}

\section{Hosted file}

randomness_extinction.pdf available at https://authorea.com/users/351399/articles/476043randomness-in-ecological-evolution-the-role-of-complexity-on-the-allee-effect
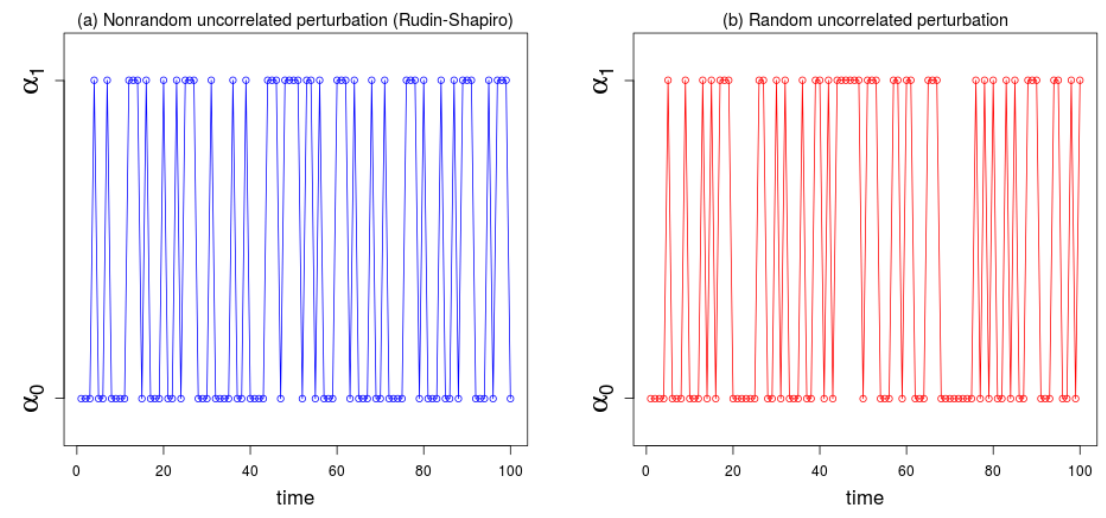

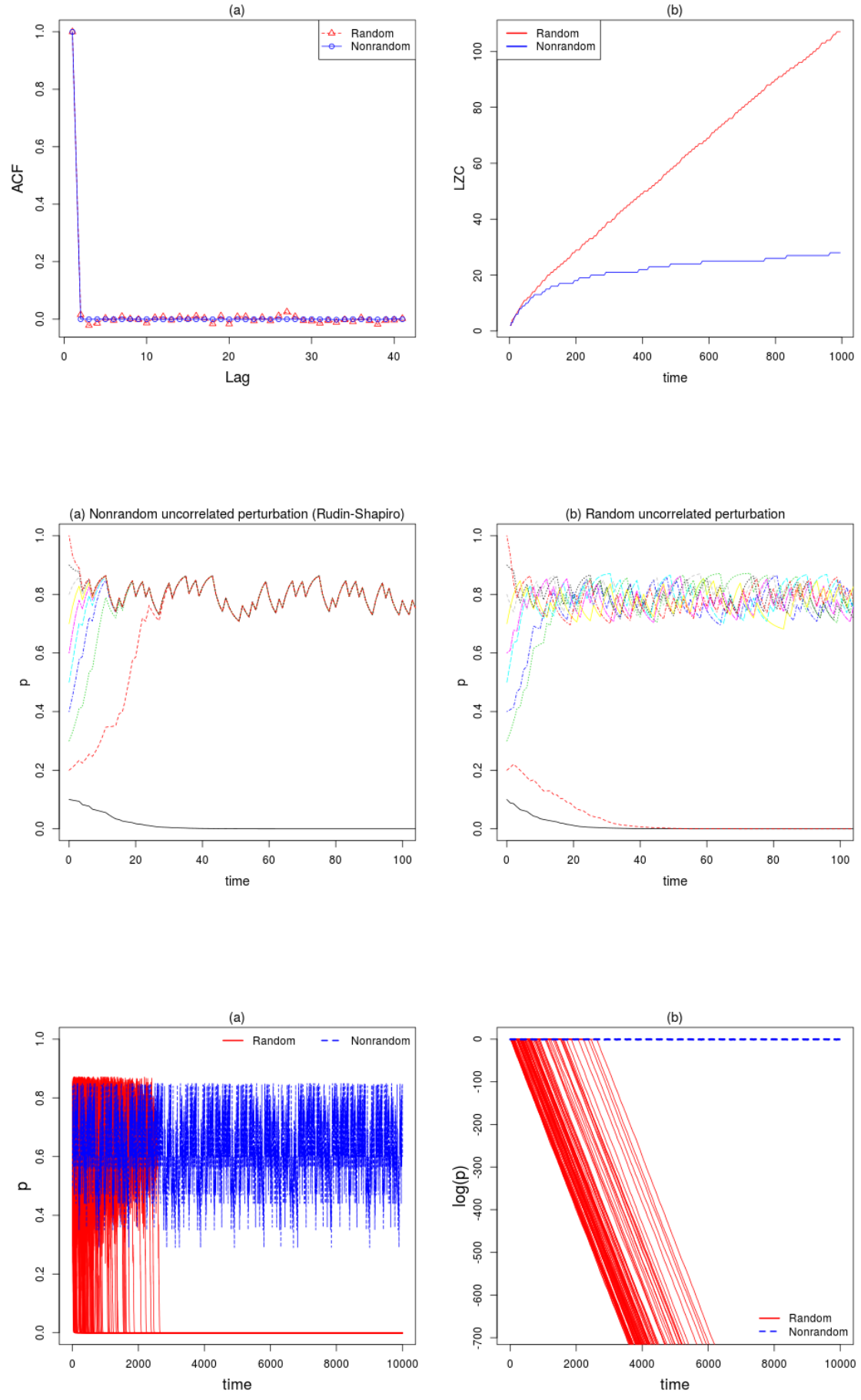

2 


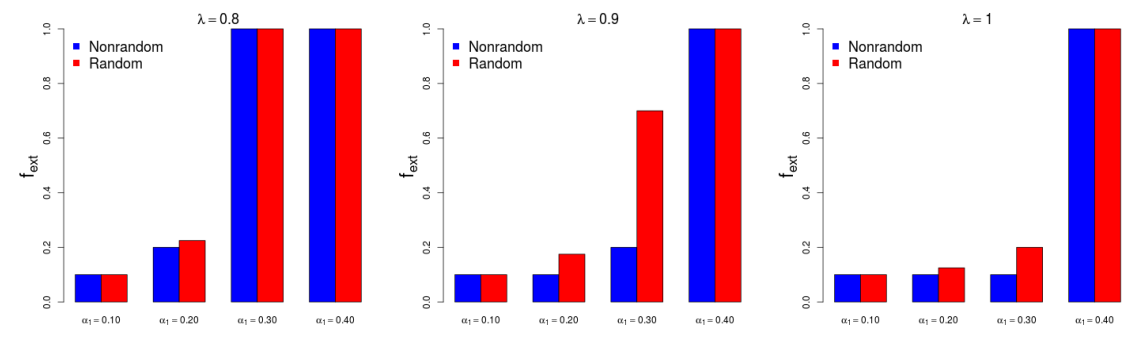

